\title{
Mudanças para 2012
}

\section{Changes for 2012}

\section{J. Vasconcelos-Raposo}

Director da Revista Motricidade - Universidade de Trás-os-Montes e Alto Douro

Com a publicação do presente número a relação da Motricidade com o CIDESD assume um novo rumo. Desde 2009 que a Revista Motricidade mantém uma relação de apoio mútuo com o Centro de Investigação em Desporto, Saúde e Desenvolvimento Humano (CIDESD). Esta parceria foi mutuamente benéfica, uma vez que serviu os propósitos de projecção na comunidade científica tanto de uma como da outra. Com a publicação do $\mathrm{N}^{\circ} 4$ do Vol. 7, esta deixa de existir nos moldes anteriormente acordados. No entanto, tanto a Motricidade como o CIDESD apoiar-se-ão mutuamente sempre que as condições para o crescimento e consolidação de cada das partes assim o deixar transparecer. Aqui, deixamos ficar o nosso sincero agradecimento ao apoio prestado.

A actual equipa editorial, desde que assumiu responsabilidades, sempre contou com a colaboração de alguns académicos e investigadores que de uma forma desprendida, e até com prejuízo pessoal, deixaram de trabalhar nos seus manuscritos para ajudar todos aqueles que confiaram na Motricidade para divulgar os seus contributos científicos. O tempo exigido e a dedicação à causa de editar uma revista científica é, efectivamente, algo que faz com que essa prestação de apoio tenda a ocorrer de forma temporária, pois é evidente que ninguém tem a obrigação de trabalhar gratuitamente para os outros, muito menos quando isso é feito em prejuízo daquilo que é imperioso para a sua progressão da carreira académica, enquanto docentes e investigadores. Relembramos que apenas com o prestígio destes académicos foi possível relançar a Motricidade para os níveis em que actualmente esta se encontra. Com o volume relativo ao ano de 2012, renovamos o nosso corpo editorial, assim como procedemos a alguns ajustes estruturais e processuais de forma a melhor responder aos anseios dos nossos colaboradores.

Ao longo destes dois anos o nosso crescimento foi rápido e consolidou-se de forma progressiva com a integração em bases de indexação de referência internacional. Em 2009 a revista estava indexada em 8 bases de dados e actualmente estamos presentes em 43. O crescimento fez-se sentir, também, a nível do volume de submissões de artigos. Desde Junho de 2009 até ao momento em que escrevemos este texto foram submetidos à Motricidade aproximadamente 600 artigos e destes apenas cerca de 375 é que tiveram encaminhamento para o processo editorial que tem início na revisão por pares. O volume de publicações efectivadas ao longo deste período deixa-nos inquietos, na medida em que os custos inerentes à edição de cada número não nos permitiu ir além daqueles que foram publicados. Dada esta insatisfação e a crescente procura por investigadores para publicar na Motricidade, optámos por aderir à publicação de uma versão digital e, eventualmente, incluir mais artigos por número, mantendo a nossa preocupação de aprofundar o nível de qualidade e relevância científica dos trabalhos a publicar. Desejamos reduzir o backlog e aumentar a qualidade da Motricidade sem comprometer a regularidade da publicação. Com a implementação das decisões agora tomadas, procuraremos, a partir de 2012, reduzir o período de tempo entre a avaliação e a sua publicação.

Com a adesão à plataforma digital, novos procedimentos entrarão em vigor, tanto no que 
se refere aos processos de submissão como de acompanhamento do processo editorial. Este novo passo implica mais rigor no que se refere à satisfação dos critérios a serem seguidos aquando da submissão dos manuscritos. Esperamos que todos os que desejam publicar na Motricidade se dêem ao cuidado de se familiarizar, detalhadamente, com as normas de publicação, mas, paralelamente, continuaremos a apoiar os nossos colaboradores referindo-os para quem os possa ajudar a ultrapassar dificuldades no processo de adequação às normas de publicação. Importa relembrar que a Motricidade ao sugerir o encaminhamento para quem possa prestar serviços de apoio no processo de formatação não assume qualquer responsabilidade, nem qualquer outro tipo de compromisso.

A partir de 2012, trabalhos com quatro ou mais autores deverão submeter uma descrição das tarefas realizadas por cada um. Procuraremos contrariar a tendência para a submissão de trabalhos realizados com pequenas amostras e cuja complexidade dificilmente justificam o número de autores. Continuaremos a privilegiar a publicação de trabalhos que primam pela apresentação de dados originais e no que se refere a manuscritos de revisão de literatura procuraremos seleccionar aqueles que se apresentarem no formato de metaanálises e onde se avalie a dimensão dos efeitos estatísticos dos resultados previamente publicados. Com maior assiduidade solicitaremos aos autores que no relato dos seus dados privilegiem o relato da dimensão dos efeitos e que evitem cingir as suas conclusões ao apoio que encontram na apresentação dos valores de significância $(p)$.

A Motricidade não publicará revisões de literatura que serviram de fundamentação para a realização de teses tanto de mestrado como de doutoramento. Aceitaremos trabalhos de revisão de literatura elaborados por pesquisadores cujo percurso e reconhecimento na comunidade científica esteja consolidado. Assim, apenas autores com um índice $\mathrm{H}$ superior a 5 são encorajados a submeter trabalhos de revisão de literatura.

A revista Motricidade assume o seu carácter interdisciplinar e por essa razão achamos pertinente organizarmo-nos por secções, nomeadamente: Desporto, Psicologia e Desenvolvimento Humano, e Saúde. Cada uma destas está dotada de autonomia suficiente para poderem promover acções no âmbito das suas respectivas áreas científicas, como por exemplo editar números especiais. No entanto, a estrutura e funcionalidade decisória sobre a aceitação dos manuscritos para publicação continuará a ser a mesma.

A partir de 2012 também abrimos a possibilidade de editar colecções de textos, em formato de livro, mas com base em materiais já publicados na Motricidade. A ocorrerem, estas poderão ter por base um convite emanado da Direcção da Motricidade assim como de eventuais propostas dos nossos colaboradores. Estamos, ainda, receptivos a pedidos de edição de números especiais em que grupos de pesquisa procurem apresentar de forma coesa a sua produtividade evitando, assim, a dispersão dos seus trabalhos por várias revistas científicas. Para esse efeito, os eventuais interessados deverão submeter à Direcção uma proposta detalhada.

O nosso corpo editorial foi revisto, procedemos a alguns acréscimos e outros, por indisponibilidade manifesta de tempo, deixaram de constar na nossa lista de editores. De qualquer forma, importa destacar o quão gratos estamos a cada um deles pelo apoio prestado.

Por razões de carácter estratégico e financeiro a Motricidade estabeleceu parcerias com instituições internacionais, sendo desde já de destacar a que fez com as Faculdades Integradas Pitágoras de Montes Claros, Minas Gerais, assim como com o Programa de Mestrado e Doutorado em Saúde da Universidade Estadual de Montes Claros. Com estes parceiros procuraremos ganhar maior visibilidade para os pesquisadores cujas áreas de intervenção se inserem nos domínios da interdisciplinaridade. 
Por fim, informamos que a partir do ano de 2012 as submissões dos manuscritos serão feitas via electrónica, a partir do website OJS (Open Journal Systems), que estará disponível online brevemente. Para esse efeito, recomendamos que todos os autores que tencionam publicar brevemente na Motricidade procurem no site da revista Motricidade (www.revista motricidade.com), as novas informações/normas para autores, bem como, o template que será disponibilizado para a submissão dos manuscritos.

(c) EY-No quando especificado em contrário e nos conteúdos retirados de outras fontes bibliográficas. 